\title{
Estrategias de interacción discursiva en la entrevista periodística en prensa escrita ${ }^{1}$
}

Rosmir Sivira Camacaro

Universidad Autónoma de Chile

Talca, Chile

\section{Resumen}

El presente estudio comprende un análisis de las estrategias de interacción discursiva aplicadas por los enunciadores de la entrevista periodística en prensa escrita. Metodológicamente se suscribe al paradigma interpretativo y estudia cinco audios de entrevista, facilitados por el diario El Impulso (Venezuela) en el año 2014, los cuales son valorados desde el estudio y la comprensión de los hechos lingüísticos, basado en los planteamientos de estructura conversacional y Turnos de Habla, así como la materialidad de la puesta en escena del discurso de la información. Los resultados muestran que se respetaron los roles del contrato social en una compleja red de interacciones semánticas de estructura flexible, sin el papel del periodista poderoso ni polémicas. Más allá de esquemas rígidos, se impuso la expresión de contenidos de calidad, co-construidos a partir de estrategias de compenetración.

Palabras clave: entrevista; estrategia; interacción; turno de habla; dispositivos escénicos.

\section{Abstract \\ Discursive interactional strategies in the written versions of journalistic interviews The present study analyzes the discursive interactional strategies applied by the enunciators of the journalistic interview in written press. Methodologically framed in the interpretive paradigm, the study focuses on the audios of five recorded interviews provided by the newspaper El Impulso (Venezuela) in 2014. These recordings are analyzed from the study and understanding of linguistic facts, based on the approaches of conversational structure and turn-taking, as well as the materiality of the staging of the}

\footnotetext{
${ }^{1}$ Estrategia de Interacción Discursiva en la Entrevista Periodística en Prensa Escrita. (Agosto 2014 _ Trabajo de grado para optar al título de Magíster en Lingüística de la Universidad Pedagógica Experimental Libertador (UPEL) en Barquisimeto, Venezuela_ a Septiembre 2020_ continuidad y cierre del análisis en la Universidad Autónoma de Chile en Talca).
} 
informational discourse. The results show that the roles of the social contract were respected in a complex network of semantic interactions with a flexible structure, without the journalist playing a role of power and avoiding polemics. Beyond rigid schemes, the expression of quality content was imposed, co-built from strategies of mutual understanding.

Key words: interview; strategy; interaction; turn-taking; stage devices.

\section{Résumé}

Stratégies d'interaction discursives dans l'entretien journalistique dans la presse écrite La présente étude comprend une analyse des stratégies d'interaction discursives appliquées par les énonciateurs de l'entretien journalistique dans la presse écrite. Méthodologiquement, elle souscrit au paradigme interprétatif et étudie cinq documents sonores issus des interviews, fournis par le journal El Impulso (Venezuela) en 2014. Ceuxci sont valorisés à partir de l'étude et de la compréhension des faits linguistiques, basé sur les approches de la structure conversationnelle et des Tours de Parole, ainsi que sur la matérialité de la mise en scène du discours de l'information. Les résultats montrent que les rôles du contrat social ont été respectés dans le cadre d'un réseau complexe d'interactions sémantiques avec une structure flexible, sans que le journaliste assume un rôle puissant ni polémique. Au-delà des schémas rigides, l'expression de contenus de qualité s'est imposée, co-construite à partir de stratégies de compréhension.

Mots-clés : entretien ; stratégie ; interaction ; tour de parole ; dispositifs scéniques. 


\section{SOBRE LA AUTORA}

\section{Rosmir Sivira Camacaro}

Periodista de la Dirección de Vinculación con el Medio de Universidad Autónoma de Chile en Talca. Magíster en Lingüística Aplicada por la Universidad Pedagógica Experimental Libertador (UPEL), Barquisimeto, Venezuela. Licenciada en Comunicación Social, mención Periodismo por la Universidad Fermín Toro (UFT), Barquisimeto, Venezuela. Diplomada en Componente Docente por la Universidad del Zulia (LUZ), Zulia, Venezuela. Áreas de investigación: Análisis de la conversación e interacción social para la construcción de ideología e imagen.

Correo electrónico: rosmir.sivira@uautonoma.cl

\section{CÓMO CITAR ESTE ARTÍCULO}

Sivira, R. (2021). Estrategias de interacción discursiva en la entrevista periodística en prensa escrita. Lenguaje, 49(1), 76-103. https://doi.org/10.25100/lenguaje.v49i1.9458. 


\section{INTRODUCCIÓN}

El encuentro del periodista con su fuente es uno de los momentos más importantes en el ejercicio de la comunicación, ya que es a través de este proceso dialogado como se puede obtener la información requerida para la producción del material. Si se aprecia la entrevista como "la instancia en la cual el investigador social formula preguntas a un sujeto, cuyas respuestas son valiosas por su condición, característica o estatus" (Reguera, 2012, p. 107), y si se le separa de su sentido como género periodístico de publicación tras un proceso de redacción y edición, esta puede proporcionar cerca del $80 \%$ de la información difundida en los medios de comunicación, según Dragnic (2010), quien señala que lo presentado a las masas, la noticia en sí, proviene en mayor medida de las fuentes vivas.

Al analizar la entrevista, se entiende entonces como una conversación o procedimiento dialogado de intercambios conceptuales, durante el cual se muestran en escena las competencias lingüísticas y comunicativas, así como las estrategias de interacción del periodista y el informante para alcanzar sus fines, casi siempre ideológicos y de imagen (Calsamiglia y Tusón, 2012; Escandell, 1996; Gumperz, 1982; Van Dijk, 1997). Sin embargo, al revisar la literatura referida al análisis pragmático del discurso periodístico, se observa que los estudios de la entrevista suelen realizarse en su formato televisivo o radial (con una materialidad distinta de la del medio impreso), como Méndez (2011), quien con el objetivo de estudiar las estrategias de cortesía y construcción de la imagen, analiza tres entrevistas del programa de televisión "Entre Periodistas", para concluir que el discurso de los moderadores estuvo centrado en los rasgos no-corteses, caracterizado por un esquema interactivo de preguntas y respuestas, carente de marcas afectivas que reflejen la construcción de la imagen del destinatario. Asimismo, se observa que la entrevista usualmente se analiza desde el producto de la información en los medios impresos (la nota publicada), mas no desde el encuentro interactivo espontáneo y de fuertes cargas semánticas.

Otras investigaciones también han demostrado que la entrevista es un proceso dialogado que permite evaluar el uso de estrategias discursivas puestas en práctica por los interlocutores, como la focalización de puntos o temas de interés en los encuentros dialogados de la televisión (Gutiérrez, 1997; Marrufo, 2005) y las estrategias de construcción del "yo" y el "nosotros" que se pueden manifestar de manera polifónica en la victimización, la solidaridad y la exclusión del "otro" (León, 2005), lo cual admite conocer la legitimación del líder político, empresarial, pedagógico o de personas interesadas en expresar un mensaje con una intencionalidad particular, bien sea explicar, describir o persuadir, entre otras.

Los estudios afines anteriormente citados no evalúan la entrevista periodística como método de indagación del medio impreso, o como refiere Charaudeau (2003), una 
instancia de enunciación discursiva del acontecimiento bruto interpretado, que es percibido por la fuente de información y que se formula respecto a un discurso que "permita dotarlo de sentido e integrarlo así a un mundo de inteligibilidad social" (p. 187). Por lo contrario, se analiza como un acontecimiento construido que ha sido transformado, proceso propio del contrato de comunicación mediática de información.

El estudio de la conversación entre periodista y fuente desde el análisis del discurso permite conocer las estructuras y mecanismos presentes, así como las estrategias y habilidades puestas en práctica por cada uno de los enunciadores, quienes, motivados por una intención, ejercen acciones con su mensaje, hecho de interés para el presente estudio, que tiene como objetivo analizar las estrategias discursivas de interacción utilizadas en la entrevista periodística de indagación del medio impreso, a partir del análisis de cinco audios en los que se aprecia la espontaneidad del discurso, para develar los significados implícitos.

El enfoque pragmático del análisis permite conocer las peculiaridades del lenguaje en uso durante el desarrollo de la entrevista periodística, así como la incidencia del contexto en la elección de una u otra destreza, de acuerdo con la situación y temática abordada, ya que el estudio comprende el análisis en los contextos: policial o de sucesos, salud, cultura, política y deportes, mismas materias en las que se clasifican las fuentes de información periodística.

\section{MARCO TEÓRICO}

$\mathrm{Al}$ analizar la entrevista periodística como método de indagación en prensa escrita suele hacerse desde el lugar de construcción del discurso de la máquina mediática, que, según Charaudeau (2003), es "aquel en el que se encuentra el texto como producto terminado" (p. 22), mas no desde el momento en el que la fuente o informante relata el acontecimiento y transmite la información. Dado que el medio de comunicación, como empresa, también prioriza sus fines de captación de la instancia receptora, se aprecia un producto con diversos campos de significación, en el cual el acontecimiento ya ha sido tratado editorialmente.

$\mathrm{Al}$ analizar la instancia de enunciación del acontecimiento, es decir, la entrevista de indagación que realiza el periodista a la fuente, se puede observar esta como una práctica comunicativa en la cual el hombre a través del habla comenta el mundo, en función de objetivos comunicativos y el ordenamiento del sentido (Charaudeau, 2003). Se entiende dicha expresión del pensamiento como un producto del razonamiento, dirigido a un grupo determinado de personas sobre quienes pretenden periodista y fuente generar un efecto.

Para comprender los mecanismos de interacción en la entrevista periodística de prensa escrita, el análisis se desarrolla a partir de los Turnos de Habla, unidad mínima del análisis, desde la cual se observa la organización conversacional de los enunciadores 
y, por tanto, el uso estratégico que hacen del discurso, para representar una noción social o acción. Dadas las condiciones físicas y la relación de contexto, se abordan en esta investigación aspectos teóricos del discurso de la información, como los Dispositivos Escénicos de Charaudeau (2003), entendidos como "el marco constituido por el conjunto de las circunstancias materiales que rigen la realización de todo acto comunicativo" (p. 225), y como las condiciones de materiales que determinan la entrevista periodística.

\section{Estrategias en el discurso}

Para autores como Sal y Maldonado (2009), en el estudio del discurso, la estrategia constituye el principio para comprender la fundamentación del análisis discursivo o el análisis de las razones por las cuales el enunciador, en la construcción de su mensaje, elige unas estructuras y no otras, al igual que el destinatario al proceder a su interpretación.

Al realizar una revisión del término, Lewandowski (2000), en su Diccionario de Lingüística, establece una distinción entre las estrategias del hablante, las cuales define como una idea consciente o inconsciente de los hablantes como base de su conducta activa; y estrategias del discurso, como los tipos de discurso referidos al interlocutor. Sobre dicha interpretación, Sal y Maldonado (2009) comentan que, con base en conceptos pragmáticos, se pueden distinguir un par de estrategias del discurso: discurso primario

81 implícito-táctico o de habla emocional, dirigido a la identificación afectiva, y discurso explicativo-argumentativo o de habla racional, apoyado en especificaciones conceptuales que permiten al hablante la elaboración de juicios críticos y actuaciones reflejas.

En el análisis de la entrevista periodística espontánea se deben evaluar entonces las expresiones racionales y de emoción como usos estratégicos del lenguaje, cuyos objetivos están relacionados con un propósito mayor dentro de la conversación, entendida como una actividad de carácter verbal interactivo. En este tenor, los referidos autores sostienen que las tácticas de valoración o presentación polarizada de los textos, indicaciones de acuerdo, formas proféticas para la pertinencia de un grupo, modos filológicos en función de las citas y corroboraciones, así como cualidades racionales mediante métodos comprobables y realizables, son expresiones tácticas en la enunciación.

\section{Turnos de habla}

La conversación, bien sea espontánea o planificada, tiene lugar en un tiempo y espacio determinados, en los cuales los interlocutores actúan de manera coordinada en diferentes niveles. Debido a que el habla consiste en un conjunto de sonidos emitidos en una secuencia temporal, la producción sonora tiene un ritmo que hace posible la percepción auditiva, que debe ser confirmada a través de los gestos y la vocalización. Esto es una expresión de lo que Sinclair y Colthard (citados en Bolívar, 2005), han analizado bajo la 
idea de que la conversación cuenta con estructura propia, puesto que como refiere Goffman (1964), "el habla está organizada socialmente, no sólo en términos de quién habla a quién en qué lengua, sino también como un pequeño sistema de acciones cara a cara, acordado mutuamente y regulado de forma ritual" (p. 135-136), lo cual forma parte del conjunto de reglas y aceptaciones mutuas de los enunciadores, que dan forma a la estructura interactiva de la conversación.

Bolívar (2005) estudia el discurso desde un modelo de estructura jerárquica, cuya unidad de mayor rango es el Texto Artefacto, elemento conversacional "que enlaza el mundo del texto con el mundo de los fenómenos" (p. 141). Se trata de un componente compuesto por varios textos que mantienen intrínsecamente el enlace entre el lenguaje y el no lenguaje desde la ubicación, propósito, estructura, significados y efectos para los participantes dentro de la matriz social. Dicha unidad la constituyen los Movimientos, que, según la referida autora, permiten identificar unidades de gran escala en el texto, las cuales expresan diversas relaciones en el discurso y pueden ser entendidas como estrategias en juego. Existen tres tipos de Movimiento: (1) movimiento tipo "A", que relaciona el texto con un acontecimiento de actualidad, también conocido como "el mundo que es o era"; (2) movimiento tipo "B", que enlaza el texto a eventos posibles, llamado "el mundo que podría ser"; y (3) movimiento tipo " $\mathrm{C}$ ", que sumado a los dos movimientos anteriores conecta el texto con acontecimientos deseables, o lo que sería igual, "el mundo que debería ser". Esta unidad la conforman las Triadas a partir del grado de elaboración de la información, lo que hace de estas el tercer mecanismo de análisis de la conversación. Pueden contener una situación actual, identificada como "S", que plantea un tema; un desarrollo, reconocido como " $\mathrm{D}$ ", que es opcional, y profundiza en elementos de la situación; y una recomendación, examinada como " $R$ ", que presenta y sugiere recomendaciones para el cierre del movimiento.

Bolívar (2005) presenta una distinción entre Tríadas de Contenido y Tríadas de Organización. Explica que las primeras componen los elementos estructurales del movimiento, ya que relacionan el texto con el mundo de los acontecimientos, mientras que las segundas se plantean en función del discurso en sí mismas y tienen una función organizativa, ya que relacionan el texto con lo que sucede en el discurso.

Con el propósito de descubrir la estructura interna de esa conversación, además de develar las partes que lo integran y las relaciones que existen entre estas, se estudian los Turnos de Habla, que, según Tusón (1997), son unidades básicas de la organización conversacional que conforman las Tríadas. A través de los Turnos de Habla se puede descubrir la estructura de una conversación como la entrevista periodística, un texto a varias voces, organizado a partir de la alternancia de estos, o lo que es igual, la sucesión de intervenciones de cada hablante; interposiciones apreciables tanto en textos escritos como hablados.

Bolívar (2005) detalla la clasificación de tres tipos de Turnos: (1) el iniciador (I) que introduce el tópico o tema y con este una posición respecto a lo abordado; (2) el seguidor 
(S) que tiene la función de mantener el tópico en la tríada y responde a la situación introducida con el turno iniciador; y (3) el evaluador (E) que tiene la función de cerrar el tópico tratado o terminar organizadamente el discurso presentado. Sobre la sucesión de estos, Tusón (1997) explica que "en la mayoría de los casos los interlocutores se suceden unos a otros sin solapamientos y sin silencios prolongados" (p. 55), lo cual parece simple, ya que el comportamiento de los hablantes está basado en normas sociales de cortesía. No obstante, para que esto ocurra se deben reconocer los Lugares Apropiados de Transición (LAT), a partir de indicios de carácter sintáctico como la complejidad o simpleza de la oración, léxicos como las repeticiones y prosódicos como la entonación ascendente o descendente seguida de la pausa, los gestos y las alusiones directas a los presentes.

Para Tusón (1997) el habla cotidiana también es espontánea y cuenta con propiedades del habla improvisada, como pausas, errores, reparaciones, falsos comienzos, repeticiones, superposiciones, a diferencia de la escritura de textos que es, en general, más controlada. Goffman (1967), por su parte, señala que las intervenciones y pausas del hablante conforman los "rituales de la interacción", puesto que son reguladas a modo de no perturbar la dialogicidad. De allí que la alternancia espontánea, propia de la entrevista de indagación y no de género, sea de valor para el estudio lingüístico y para el presente trabajo.

\section{Dispositivos escénicos}

En el acto comunicativo del diálogo, como intercambio entre dos instancias, intervienen las intenciones indagatorias del periodista y los propósitos del entrevistado, que en el caso de figuras públicas como los políticos pueden ocultar o desmentir aquello que afecta su imagen, por lo que el medio de comunicación, basado en su "postulado de democracia", busca develar lo que parece oculto por la fuente de información. Sin embargo, Charaudeau (2003) sostiene que estos organismos también se definen dentro de una "lógica comercial" de captación de público. "Su actividad, que consiste en transmitir información, que puede estar dada, o ser buscada o bien provocada, se vuelve sospechosa porque su finalidad responde a otro interés que no es servir a la democracia" (p. 72). En tal sentido, el autor niega la presencia de inocencias.

$\mathrm{Al}$ analizar el discurso de la información, el autor hace una clasificación desde el conjunto de las circunstancias materiales que rigen la realización de todo acto comunicativo, la cual es denominada Dispositivos Escénicos, que en el caso de la comunicación mediática estima condicionamientos situacionales y se estructura en los soportes radio, televisión y prensa escrita.

En la descripción de las condiciones situacionales del contrato mediático, Charaudeau (2003) destaca la voz como característica principal del soporte radial, puesto que "la voz revela a la escucha, atenta o inconsciente, los movimientos afectivos, 
sentimientos favorables o desfavorables, el temblor de las emociones, la frialdad o la pasión, las vibraciones de la mente, la sinceridad o el engaño" (p. 227), relaciones que se hacen presentes en la entrevista entre periodista y fuente de información, como método de indagación.

El autor plantea Dispositivos Escénicos en Radio que, por tanto, son de interés para la presente investigación por permitir apreciar la espontaneidad estratégica del encuentro dialogado, espontaneidad que no es posible apreciar en publicaciones de prensa escrita. Expone que la entrevista periodística de radio está determinada por el control mediático y la disposición de los participantes. Bajo tales condiciones, presenta ciertas variantes en la entrevista, que también son aplicables a ella como método de recolección de información para el medio impreso. Explica que:

Hay un entrevistador cuyo rol consiste en intentar obtener del invitado el máximo de informaciones y en hacer aparecer las intenciones ocultas, por lo que también él jugará un juego de discursivo sutil en el que se alternan o se mezclan falsa inocencia, falsa complicidad, provocaciones e intentará poner de relieve las contradicciones del invitado. (Charaudeau, 2003, p. 229).

Se trata de un encuentro comunicativo en el que se hace necesario el uso de estrategias discursivas que permitan al entrevistador tener el control sobre la entrevista y así obtener la información deseada. El autor añade que el entrevistador que asume el rol de interrogador ingenuo, como si él mismo fuese un miembro del público receptor de la máquina mediática, aborda el papel de traductor y deja ver esto al entrevistado para que comprenda que cumple con su deber de simplificar aún más la explicación, lo que se interpreta como una estrategia de acercamiento a su propósito. También puede asumir un rol interrogador coercitivo.

Otra habilidad del entrevistador es desempeñar el rol discursivo de intimidad, complicidad o de entusiasmo y, con base en el conocimiento que tiene del tema, hacer que aparezca una explicación que exponga un hecho ante la intención del entrevistado de escapar constantemente del interrogatorio en el que el periodista lo encasilla, basado en la idea de que este trabaja para informar a quien está desinformado. En este punto, Charaudeau (2003) señala que el entrevistador igualmente puede asumir el juego de las emociones, a través de la formulación de preguntas y comentarios que le permiten obtener un testimonio. También es posible que en "la entrevista de estrellas", se apoye en su conocimiento y utilice estrategias discursivas de conciliación o complicidad, incluso provocación, a fin de penetrar en el espacio privado y el universo íntimo de la persona. Es decisión del entrevistador escoger hasta qué punto resulta legítimo apoyarse en rumores o estereotipos.

En la entrevista como método de recolección de información no existen límites de tiempo. Cuanto más complejo sea el hecho a comunicar, más profundo será el 
pensamiento y mayor tiempo de palabra requerirán, según lo explica Charaudeau (2003), quien da importancia al valor simbólico que se atribuye a la palabra.

\section{Metodología}

El enfoque del presente estudio es cualitativo, ya que está centrado en la interpretación y comprensión de los hechos observados, basado en el contexto, espacio en el que según Rusque (2003), se aprecia cómo los individuos construyen la realidad social a partir de procesos interactivos que son parte de la vida cotidiana. De esta manera, se estima que son los sujetos quienes orientan significativamente la acción.

Al valorar la entrevista periodística como método indagatorio complejo, en la cual se intercalan actuaciones lingüísticas, una heterogeneidad social y diversidad de perspectivas, es pertinente asumir el muestreo intencional, ya que como explica Rojas (2010) estas investigaciones no responden a criterios de representación numérica, sino a su propósito, que pauta también la selección de aquellos sujetos que puedan aportar información relevante. De allí que en la selección de los sujetos (cuya identidad ha sido resguardada) prevalezcan criterios definidos en atención a los objetivos planteados.

Para el presente estudio se seleccionan como evidencia cinco audios de entrevista (de las fuentes de información policiales, salud, cultura, política y deportes), facilitados por el diario El Impulso, de Barquisimeto, Venezuela, en el año 2014. En dicha selección se estiman los años de experiencia de los profesionales y reconocimientos otorgados por su desempeño laboral, además de valoraciones del tópico para el momento de realizar la entrevista. Dichos audios son transcritos basados en la propuesta de Tusón (1997), la cual permite emplear grafías para señalar aspectos fonéticos de interés para el análisis.

Con base en el enfoque cualitativo se aborda como técnica de análisis de la evidencia el análisis de contenido o análisis de discurso, que según Reguera (2012), es "un conjunto de procedimientos cuyo objetivo es producir un META-TEXTO analítico en el que se representa el corpus textual de una investigación de manera transformada" (p. 96). Se estima que para analizar, comprender e interpretar un hecho lingüístico se debe generar un conocimiento del mismo lenguaje, es decir, un texto del texto que permita presentar esa realidad o significados de una manera detallada y funcional. La evidencia se segmenta en turnos de habla, etiquetados según su enunciador (periodista o fuente), clasificación de la fuente, fecha de realización de la entrevista y número del turno de habla en la entrevista; y se analiza a partir de dos matrices diseñadas por la autora, con el propósito de descubrir sus significados implícitos en función del objetivo planteado.

El primer instrumento se diseña con el fin de examinar los mecanismos de interacción presentes en la entrevista periodística del medio impreso, a partir de la alternancia de Turnos de Habla, tal y como se observa en la Tabla 1. 
Tabla 1. Matriz $\mathrm{N}^{\circ} 1$. Estudio de los turnos de habla

\begin{tabular}{|c|c|c|c|c|c|c|}
\hline \multirow{2}{*}{$\begin{array}{l}0 \\
0 \\
0 \\
\Xi \\
\Xi \\
\Xi\end{array}$} & \multirow{2}{*}{ 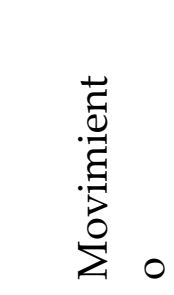 } & \multirow{2}{*}{ 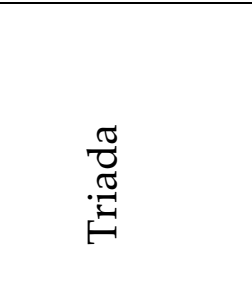 } & \multicolumn{3}{|c|}{ Tipo de Turno } & \multirow{2}{*}{ 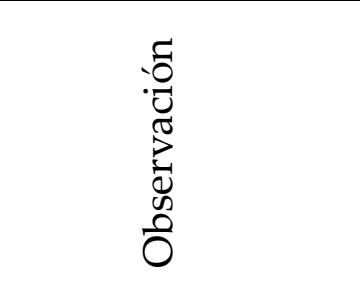 } \\
\hline & & & I & S & $\mathrm{E}$ & \\
\hline & $\begin{array}{l}\text { Unidad } \\
\text { que } \\
\text { contien } \\
\text { e una o } \\
\text { más } \\
\text { triadas. }\end{array}$ & $\begin{array}{l}\text { Segmento } \\
\text { constituido } \\
\text { por turnos. } \\
\text { Cada tríada } \\
\text { contiene un } \\
\text { tópico, una } \\
\text { estructura } \\
\text { interna y } \\
\text { una función } \\
\text { en el } \\
\text { discurso. }\end{array}$ & $\begin{array}{l}\text { Introduce el } \\
\text { tópico: } \\
\text { presenta y } \\
\text { organiza. }\end{array}$ & $\begin{array}{l}\text { Mantiene el } \\
\text { tópico. } \\
\text { Presenta } \\
\text { información } \\
\text { relevante y } \\
\text { evalúa el } \\
\text { turno } \\
\text { iniciador. }\end{array}$ & $\begin{array}{l}\text { Cierra el } \\
\text { tópico o } \\
\text { termina } \\
\text { parte del } \\
\text { discurso. } \\
\text { Evalúa el } \\
\text { turno y da } \\
\text { paso a un } \\
\text { cambio en } \\
\text { la } \\
\text { conversac } \\
\text { ión }\end{array}$ & $\begin{array}{l}\text { Cómo se da la } \\
\text { relación de los } \\
\text { hablantes en } \\
\text { función de los } \\
\text { turnos, anteriores } \\
\text { y el esquema del } \\
\text { texto. Uso } \\
\text { estratégico de los } \\
\text { recursos. }\end{array}$ \\
\hline
\end{tabular}

Fuente: Sivira (2014), a partir de Goffman (1964, 1967), Bolívar (2005) y Tusón (1997)

La segunda matriz se construye a partir de la propuesta de Dispositivos Escénicos para Radio y variantes de la entrevista, descritos por Charaudeau (2003), que refiere que estos son producto de la espontaneidad y la estrategia, tal y como se observa en la Tabla 2. 
Tabla 2. Matriz N $\mathrm{N}^{\circ}$. 2. Estudio de las estrategias discursivas a partir de Dispositivos Escénicos

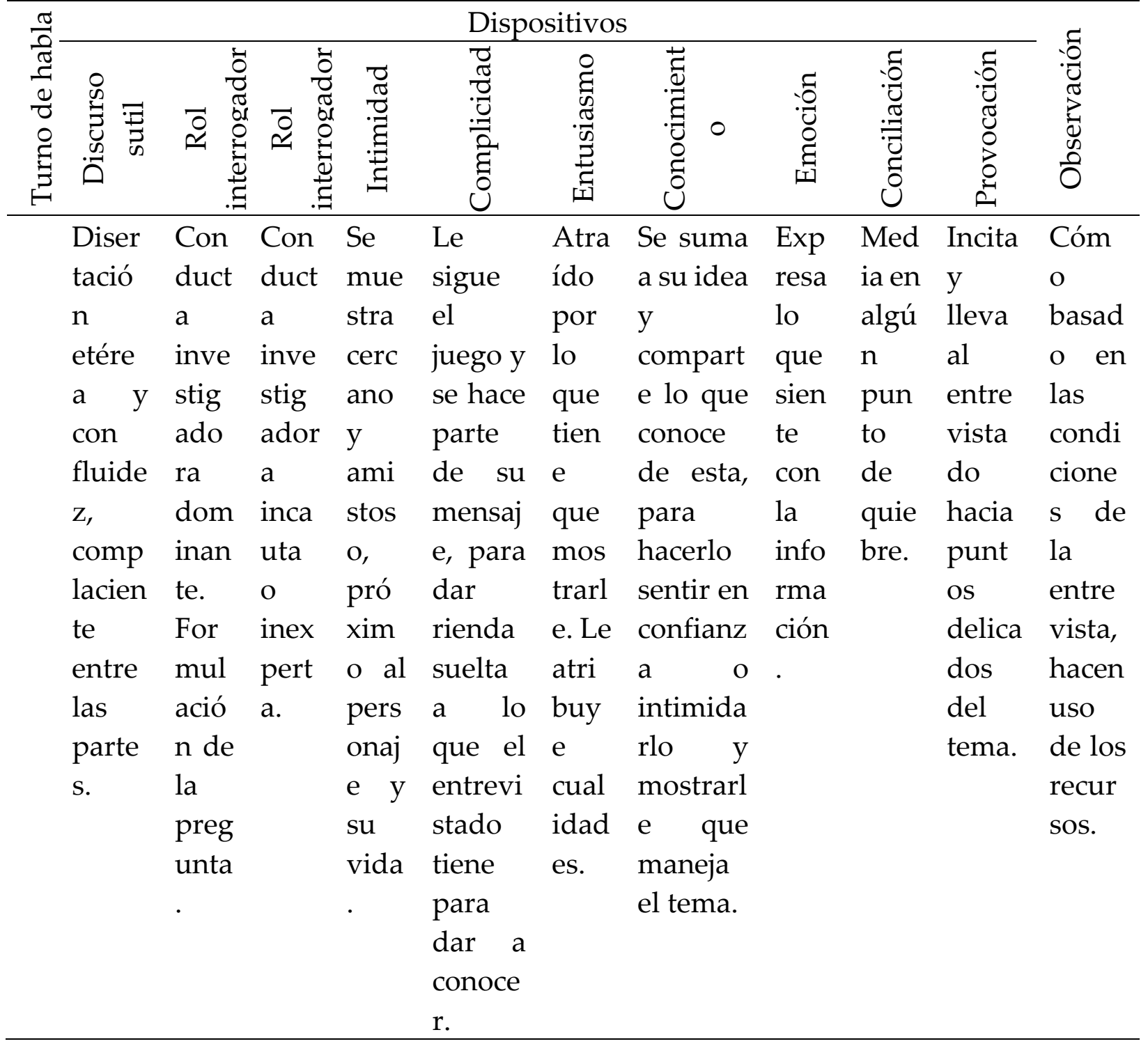

Fuente: Sivira (2014), a partir de Charaudeau (2003)

\section{Resultados}

\section{Turnos de Habla}

En su tarea por obtener la información necesaria para desarrollar la nota periodística y ante el compromiso de la fuente de representar el grupo al que pertenece, se encuentran en las conversaciones analizadas mayor uso de relaciones o referencias sobre acontecimientos de la actualidad, que según Bolívar (2005) conectan "el texto a eventos posibles", lo que corresponde a Movimientos tipo " $\mathrm{A}$ ", en los que se habla del "mundo 
que es y era". Sin embargo, también se hacen presentes, con menos frecuencia, los Movimientos tipo " $\mathrm{B}$ " $\mathrm{y}$ " $\mathrm{C}$ ", que relacionan el texto con eventos posibles o el "mundo que podría ser", y con los acontecimientos deseables o "el mundo que debería ser", respectivamente. Los mencionados hallazgos se observan en la Figura 1:

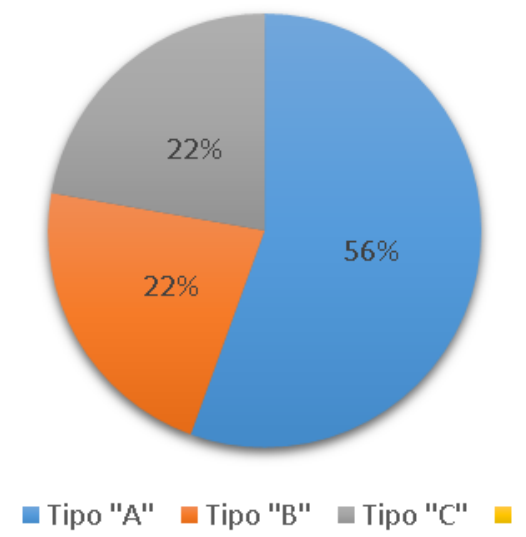

Figura 1. Movimientos de la conversación

Respecto al análisis de las "Tríadas" como mecanismos de organización de la conversación, en la mayoría de los Movimientos analizados no se presenta su evaluación, por lo cual se puede decir que más que un esquema u organización, impera la información. Allí reside la razón por la que dos de las entrevistas presentan exclusivamente Tríadas de Contenido, que según Bolívar (2005) "relacionan el texto al mundo de los acontecimientos [...] tienen funciones distintas: hacer afirmaciones sobre un evento; elaborar en torno a estas afirmaciones; y hacer o sugerir afirmaciones" (p. 149), mientras otras dos entrevistas presentan ambas configuraciones de tríadas. Sólo una evidencia muestra únicamente Tríadas de Organización que, según explica la citada autora, tienen una función organizativa que esquematiza el discurso, con lo cual conecta el texto con lo sucedido en el discurso y sus consecuencias.

Respecto a los Turnos de Habla, se observa que no siempre se mantiene la estructura tradicional Iniciador-Seguidor-Evaluador, ya que más allá de los esquemas se imponen las intenciones: informar y obtener la información.

Los sujetos emplean estrategias de cortesía y fatemas para no abandonar los tópicos de su interés, hasta obtener la información deseada. Allí reside la razón por la cual $81 \%$ de los 275 turnos analizados son Turno Seguidor, hallazgos que se muestran en la Figura 2: 


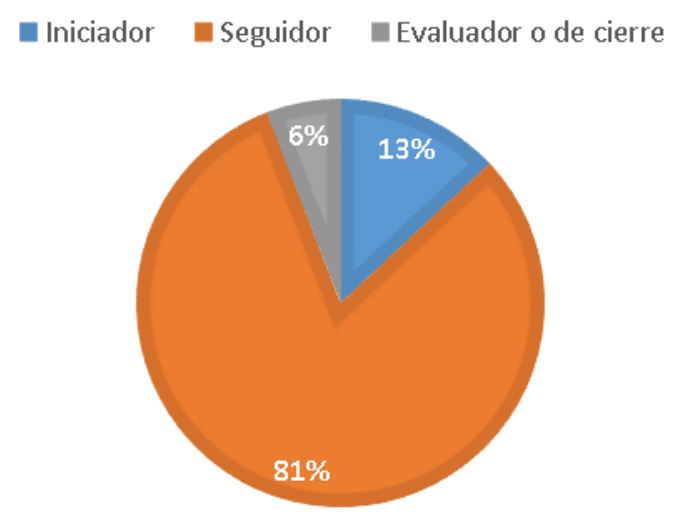

Figura 2. Turnos de Habla

A propósito de mantener los Turnos Seguidores, también se aprecia el uso de deícticos para señalar elementos, personas y lugares, de acuerdo con el argumento de interacción del hablante, que según Tusón (1997) se trata de contextos sociales y espaciales que comparten a manera de referencia, a fin de corroborar que la recepción del mensaje es la correcta, como cuando en la entrevista de cultura se introduce un nuevo punto de un tema que se venía dialogando: la Orden Jacinto Lara, otorgada por el gobierno venezolano al artista entrevistado. La periodista se refiere al tiempo trascurrido desde que el artífice comenzó a exponer su proyecto hasta la entrega del premio. Emplea el deíctico de lugar "acá", a pesar de que la interrogación es formulada sobre el tiempo; la intención es connotar progreso y traslado de un punto de inicio a otro de consolidación. La estructura resume una Triada de Contenido, ya que presenta un tema (el tiempo) y se profundiza en este, por lo que elabora un contexto en torno a esta interrogante.

Entre los hallazgos, también se aprecia cómo el periodista puede asumir el papel de informante, de acuerdo con el nivel de confianza y espontaneidad de la conversación, complementando la respuesta del entrevistado y creando un Turno Seguidor a través de Lugares Apropiados de Transición (LAT), que según Tusón (1997) se reconocen a través de indicios como la complejidad de oraciones, entonación y otros, escenario que se traduce en la compenetración de los hablantes a partir del conocimiento y el sentido de la conversación, lo que algunos teóricos reconocen como un único turno construido a dos voces o de forma colaborativa.

Otro LAT observado se presenta en la entrevista de policiales, en la cual al hablar periodista y funcionario del cuerpo de seguridad sobre el asesinato de un delincuente fugado de un recinto carcelario, la fuente da mayores detalles de la detención y con ello continuidad del tópico, mientras que el interrogador complementa referencias cronológicas en la respuesta y propicia la prolongación del tema. No vale como interrupción, sino como compenetración de los interlocutores, en conocimiento y sentido.

Es de destacar que los periodistas también ejercen este tipo de intervenciones para ratificar que se encuentran en lo correcto y que comprenden acertadamente lo dicho por 
la fuente, lo que podría ser valorado como Turnos Seguidores, que evalúan a la vez que cierran las tríadas.

\section{Dispositivos Escénicos de la Entrevista}

$\mathrm{Al}$ analizar las entrevistas, se observa que es el recurso de "intimidad" el más recurrente en uso, con lo cual se estima que entre el periodista y la fuente pueden existir cercanías profesionales que permiten indagar sobre tópicos especiales, sin infringir las barreras puestas por la misma fuente. Destaca entonces el conocimiento que debe tener el periodista del tema en cuestión y de la persona a la cual está entrevistando, a fin de hacer uso de este dispositivo cada vez que el entrevistado se lo permita, con base en las estructuras internas de la conversación y los indicios de contextualización detectados.

Se estima el dispositivo "entusiasmo" como el segundo en recurrencias, debido a que tanto periodistas como entrevistados se muestran interesados por el tema en discusión, en especial los representantes de los medios de comunicación, quienes procuran crear un ambiente cómodo y de confianza en el que los informantes se sintiesen realzados.

El "rol interrogador ingenuo" es el tercero de los más usados, con lo cual los periodistas no abandonan su rol de preguntadores, ni tampoco el control de las entrevistas. Sin embargo, en la formulación de las preguntas y en sus expresiones de continuidad, adoptan posturas cándidas, a fin de que la fuente no se sienta acechada o agobiada durante la entrevista y aporte la información requerida para la nota periodística.

No se valora el dispositivo de "complicidad" en esta jerarquización dado que casi la totalidad de estos corresponden a interrupciones cómplices de la entrevista de cultura y estilo de un único periodista. Sin embargo, el uso del recurso se valora como un fatema, que según Kerbrat-Orecchioni (citado en Tusón, 1997), se aprecia como ruido o vocalización con valor interactivo, ya que suele ser utilizado para señalar extrañeza, sentimiento, duda, incredulidad o indicar que se sigue el mensaje, por lo que funciona como continuador y anima al otro a mantener el uso del turno de habla, tal y como se observa en la Figura 3: 


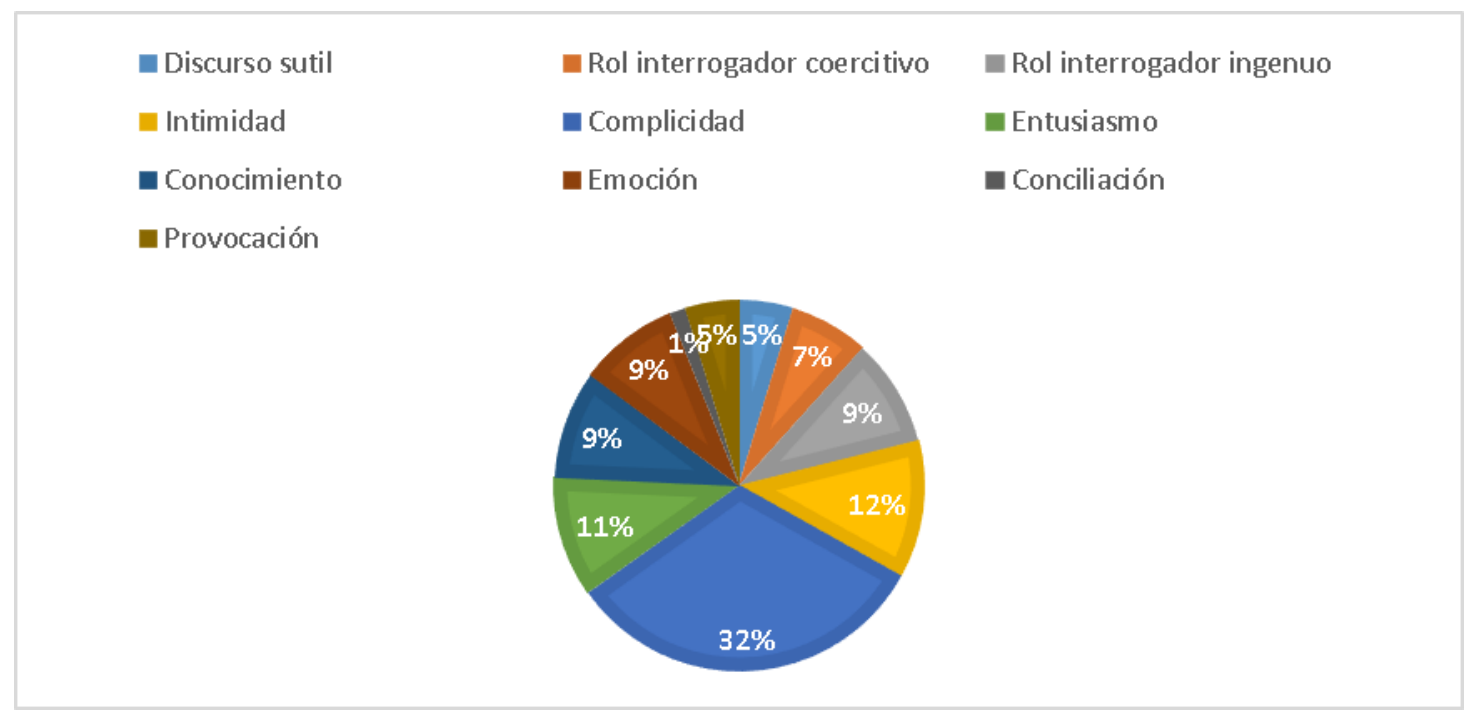

Figura 3. Dispositivos Escénicos en la entrevista

Los tres dispositivos de mayor aparición dan muestra de que en las entrevistas analizadas el rol de periodista poderoso no es determinante y que en el medio impreso, por el contrario, se aprecian posiciones mediadoras y de supuesta ingenuidad, que resguardan los planteamientos realizados, a fin de no perder la proximidad lograda en la conversación.

Asimismo, la connivencia como mecanismo de confabulación o seguimiento es un recurso de uso recurrente por parte de ambos enunciadores. Se ejerce bajo términos positivos, en los cuales cada parte es consciente de las consultas y propuestas del otro, como cuando en la entrevista de cultura es el entrevistado quien dialoga sobre el apoyo que ha recibido su trabajo en diversos sectores, entre estos del gremio de periodistas (dispositivo de complicidad). El entrevistador toma la idea como un halago (dispositivo de emoción) y se atribuye la cualidad sin temor, motivado al nivel de comodidad de la conversación, lo cual es confirmado por la fuente (dispositivo de complicidad).

Durante el análisis se aprecia cómo los enunciadores desarrollan esquemas estratégicos de diálogo, basados en las circunstancias co-construidas durante el acto comunicativo, por tanto puede decirse que se trata de estrategias racionales, a su vez apoyadas en lo implícito-táctico, con base en lo planteado por Sal y Maldonado (2009).

\section{Discusión}

La consideración de los resultados obtenidos tras la aplicación de ambas matrices permite señalar que el carácter espontáneo dado en las cinco entrevistas no resta a estas su coordinación, ni intenciones implícitas de cada participación de los enunciadores.

Con fundamento en los preceptos teóricos de Goffman (1964, 1967), Bolívar (2005) y Tusón (1997), y basado en el análisis de la evidencia, se señala que el fin es el contenido. La cantidad de intervenciones realizadas por los entrevistadores supera las hechas por 
los entrevistados; los primeros dirigen los encuentros, inician y cierran la conversación. Sin embargo, en contenido y extensión de turnos de habla son las fuentes las de mayor participación, porque lo perseguido es la respuesta, insumo de trabajo para el periodista.

En la interacción, periodista y fuente hacen uso del tuteo como muestra de proximidad y afinidad sobre el tema, lo cual da crédito del reconocimiento de ambas partes como conocedoras de su labor y responsabilidad en el contrato social que los convoca en la entrevista. Se trata de un juego de confianzas, cortesías y halagos, como se observa en la Tabla 3.

Tabla 3. Ejemplo 1

PLC062014-81 == perfecto, además ¿continúas con el programa de radio todavía verdad?

FAC062014-81 ==el programa de radio...-

PLC062014-82 == ¿Cuánto tiempo tiene? Para colocarlo por acá

FAC062014-82 =e el programa de radio va para siete años

PLC062014-83 == para siete años

Lo acá planteado contradice lo expuesto por Méndez (2011), quien sostiene que el discurso de los entrevistadores puede mostrar rasgos no-corteses, representados por un esquema interactivo de preguntas y respuestas, desprovisto de marcas afectivas. Sin embargo, fundamentado en Charaudeau (2003), que niega la presencia de inocencias por parte de los enunciadores, se observan actos estratégicos de cortesía, justificados en el rol que cada enunciador desempeña dentro de la conversación: quien pregunta y quien responde.

$\mathrm{Al}$ ser los periodistas quienes inician el diálogo con una interrogante, hacen gala de aparentes ingenuidades para mostrarse como personas accesibles y deseosas de obtener la información que el otro aporta. Sin embargo, es importante estimar que según Van Dijk (1997), los reporteros manejan formas públicas e institucionales del texto y del habla, mucho más poderosas que las usadas por el hablante común, como se aprecia en la Tabla 4, expuesta a continuación. 
Tabla 4. Ejemplo 2

FPP032014-04 == Exacto 1 Venezuela le pidió también a Celaya el el:: puesto para que la OEA hablará y se le oyera a él 1 y nadie critico 1 nadie protesto por él ll Ahora una diputada de la república 1 La diputada electa con la mayor votación 1 NINGUNO de los que está sentado allí sacó más votación que María Corina Machado ¿no? ll Ella va a la OEA 1 Panamá le ofrece su puesto 1 por razones de cortesía diplomáticas:: en primer lugar no se le deja hablar 1 (ehmm) se dijo que no iba a ser pública sino privada, pero ni siquiera privada sino penas unos minutos pudo decir algo (ehhmss) Se le:: se señala entonces / que por haber aceptado esa cortesía diplomática de Panamá ella ha aceptado un cargo público en otro país 1 Es traidora a la patria (le) y por tanto deja de ser diputada [aspiración] Por cierto que el artículo que describe del 191 no es para esos ::casos:: mucho menos 1 No es temporal a 1 Para cuando un diputado lo designan (le) ministro, para un cargo público, embajador 1 en ese caso 1 por supuesto 1 Iris Valera era era:: diputada y la nombraron ministro para :: penitenciario y tuvo que abandonar el:: la:: el curul 1 Pero eso no ocurrió con María Corina Machadofue diputada ¿no?

_También la defensora del pueblo 1 también creo que

Se observa cómo el entrevistado ha expuesto que el personaje en cuestión ha asumido un cargo en el parlamento (dispositivo de conocimiento). Sin embargo, el entrevistador, interroga con aparente inocencia (dispositivo rol interrogador ingenuo) sobre el mismo punto y apoyado en su conocimiento, tras el aprovechamiento de un breve silencio en la intervención de la fuente, a fin de enfatizar un tema que resulta de valor para la conversación, puesto que la interposición del interrogado, un abogado, se basa en el incumplimiento de la ley por parte del gobierno venezolano, contra quienes simbolizan la oposición en el país. Se trata de una intención descubierta por efectos de la entonación, discurso y acentuación.

De allí que se refiera que no todos los contenidos consultados por el periodista son de su interés y sus menciones son estrategias encubiertas en falsas inocencias. Los enunciadores, por tanto, introducen entre tríadas, temas que le sirven de medio para presentar tópicos de su interés y que se revelan en el análisis de los Movimientos construidos en el diálogo, como el citado en la Tabla 5. 
Tabla 5. Ejemplo 3

PCS052014-02 == ¿Y en diez años cómo has visto tú el cambio en la PTJ hasta ahora?

FPS052014-02 $==\ldots .==$ ¿En todos los aspectos, o en alguno en específico? L

PCS052014-03 == En todos los aspectos, sobretodo en la parte laboral de ustedes, co ¿Cómo ha sido? ¿Han obtenido más beneficios? O ¿tienen más trabajo?

FPS052014-03 == Realmente en la parte laboral la única mejora fue el año pasado con la homologación y aumento de sueldo que fue sustancial $<$ pausa> fue :: / verga el sesenta o setenta por ciento o setenta y cinco por ciento, una vaina así.

PCS052014-04 == ajá

FPS052014-04 == Este :: 1 sin embargo, no alcanza para cubrir las necesidades de cada quien.

PCS052014-05 == Exacto. ¿Y ustedes se ven afectados por este poco sueldo? En el caso por ejemplo que muchas veces los intentan sobornar, mucho de los funcionarios matraquean a las personas ¿crees tú que puede ser por la falta de esto, la falta de sueldo?

En el ejemplo, se observa que el tema laboral, bajo la perspectiva de las condiciones de trabajo, no es el punto focal de la indagación del periodista, sino que se trata de un falso comienzo como Turno Iniciador, que sirve de conducto para inducir al entrevistado a hablar sobre vicios de la profesión, entre estos el soborno. Para apreciar dicha intención, es preciso analizar la interacción como una unidad a gran escala o movimiento discursivo, que en este segmento de la entrevista es de "Tipo A", ya que expresa "el mundo que es y era". También se observan expresiones del mundo que podría ser", al comparar su situación con la de funcionarios de seguridad de otros países.

No obstante, cuando en la conversación se presentan temas de suma delicadeza, pueden mostrarse vacilaciones en el habla de los enunciadores. Se desacelera el ritmo de la entrevista y las partes recurren a herramientas como pedir la repetición de los planteamientos expuestos para ganar tiempo y pensar la respuesta o persuadir al interrogador, como se evidencia en la Tabla 6.

Tabla 6. Ejemplo 4

PCS052014-06 : == Sí, es que eso es un coño cien mil bolívares al año. Y (inaudible) y cuando alguno de ustedes, ni quiera Dios en tu caso (ac), lo los asesinan ¿Cómo hacen? ¿Les siguen pagando a sus familias? ¿Le siguen dando beneficios a la familia?

FPS052014-06 = ¿Cuan..- cuando qué?

PCS052014-07 = Cuando matan a algún funcionario de la PTJ, ¿le siguen pagando el sueldo a la familia? (ac) 
Son diversas las imprecisiones que pueden darse en una conversación, por lo que los enunciadores deben ir "negociando" el mantenimiento o cambio del tema, de tono, de finalidad e ir interpretando sobre la marcha las intenciones ajenas, así como manifestando las propias (Tusón, 1997). Por tanto, en este proceso de interacción los enunciadores también reconocen implícitamente los tópicos que podrían resultar delicados o álgidos a partir de las inferencias o indicios de contextualización, por lo que su abordaje se hace de manera estratégica. Como cuando el periodista se apoya en el tema económico para hablar de un posible tabú: el asesinato de un funcionario de seguridad. A pesar de atenuar el mensaje a través de la formulación de su consulta, este resulta de difícil tratamiento para el entrevistado, quien en el ejemplo anterior solicita de manera indirecta la reformulación de esta. Tal petición se aprecia como una actitud evasiva.

Para que un discurso sea comprendido por el receptor, se debe establecer un terreno común que permita a los otros participar en el proceso. Respecto a las acciones que se pueden generar, Van Dijk (1999) manifiesta que:

Emitir palabras y oraciones en el texto y la conversación, en una situación específica, es también, y al mismo tiempo, la realización de una gran cantidad de acciones sociales, además de la de participar en la interacción social... se hacen aseveraciones promesas o amenazas, y esos actos de habla están específicamente definidos en términos de las condiciones sociales de los participantes, a saber, sus creencias mutuas, deseos, intenciones, evaluaciones y objetivos que tienen implicaciones sociales. (p. 263).

Cualquier declaración, manifestación o confesión hecha en el discurso, se toma en cuenta como una acción del habla que mejora o deteriora las relaciones emisor-receptor. En consecuencia, se manejan puntos propios de la cognición y personalidad del público, lo que conlleva un delicado proceso social, en el cual el control ideológico interfiere directamente en dichos actos para fijar que las relaciones entre los participantes están ideológicamente determinadas por los reflejos de las dimensiones del contexto.

Los tópicos de complejo tratamiento son entonces planteados con base en recursos personales y hasta ideológicos, a fin de incursionar en la intimidad de la fuente y "doblegarla" para llegar al punto deseado, como se aprecia en el texto citado en la Tabla 7: 
Tabla 7. Ejemplo 5

PCS052014-22 == Uhm ok, David y en tu caso ¿qué te llevó a ser un policía del estado, o policía científico en este caso?

FPS052014-22 ==E :: coño no sé, porque esa vaina de carajito (llamada telefónica) ¿cuánto es pana? 50, ahí te pasé dos- este:: coño mi mamá decía que de carajito siempre me gustó esa vaina, yo siempre dije que quería ser del FBI pero aquí como no existe esa vaina, el FBI sus similares es PTJ (AC). < ..> Y si me preparé, me gusta mi trabajo y quedé a pesar de que me han hecho unas ofertas o he tenido muy buenas ofertas y no me he ido pues.

PCS052014-23 == Y cuando les hacen, cuando aprehenden a una persona o a un delincuente, ¿cómo te sientes tú?

FPS052014-23 $==\ldots==$ ¿cuándo qué?

PCS052014-24 == Cuando agarras un delincuente, cuando hacen justicia, resuelven un caso, ¿cómo te sientes?

FPS052014-24 == En cierto modo satisfecho, en otros modos en otros casos frustrante porque independientemente muchas veces uno hace el trabajo, por alguna cosa $u$ otra que los testigos no fueron al juicio, que o quien sabe qué, a muchos los dejan en libertad, por ejemplo el que mataron ayer en el Sambil tiene cuatro antecedentes, uno por robo del 2005 y otro por robo del 2007, o sea que no duró ni dos años preso por robo (AC).

La pregunta planteada por el entrevistador tiene como intención consultar al entrevistado como persona y sus motivaciones profesionales desde un terreno de respeto (dispositivo rol interrogador ingenuo), por lo cual el entrevistado, un policía, cede a la intención del periodista y cuenta las razones de su vocación, que inicia desde la infancia, con un prototipo norteamericano.

El periodista antepone el término "justicia", en una reiteración de su interrogante, a fin de obtener la confianza del otro y hacerle entender que respeta su labor. Mantiene la intención de mostrarlo como un sujeto sensible, lo que también atiende a lo expuesto por Goffman (1967), quien señala que los eventos dialogados están constituidos por rituales que indagan por información del otro para así definirlo en sociedad. Como resultado de la estrategia planteada, la fuente declara que el sistema no satisface sus expectativas y presenta fallas, deja en libertad a los delincuentes o no les da el castigo debido (dispositivo de intimidad), con lo cual el entrevistador obtiene información de su interés indirectamente, mientras que ambos enunciadores construyen identidad y sentido del mundo que los rodea como seres sociales (Calsamiglia y Tusón, 2012; Tusón, 1997). 
Pero el entrevistado también puede no sentirse cómodo con el interrogante que le han formulado, con lo cual cambia su mecanismo de reacción, como se exhibe en la Tabla 8:

\section{Tabla 8. Ejemplo 6}

PCS052014-07 = Cuando matan a algún funcionario de la PTJ, ¿le siguen pagando el sueldo a la familia? (ac)

FPS052014-07 = Sí, le queda :: le queda una pensión a la familia, como en todo los organismos de seguridad que es una pensión de familia. Para los hijos, la esposa este :: pero que también es un lio como todo, es un proceso y como todo pues. I

Ante un contrato social definido y aceptado por las partes al interactuar, entrevistador y entrevistado ejercen cada uno su rol. Sin embargo, la calidad de los contenidos durante la instancia de enunciación discursiva parte de la comodidad que estos experimenten. Se observa que tras hacer mención de aspectos como: muerte o asesinato, como en el segmento de entrevista antes mencionado (dispositivo de provocación), el periodista pierde cercanía con la fuente y la complicidad en la interacción. En este caso, la respuesta dada por el entrevistado explica sin mayor detalle lo que el periodista desea conocer (dispositivo sutil). Cumple con su papel de informante, pero se aleja discursivamente del entrevistador.

Contrario a lo que ocurre al desarrollarse largas respuestas, también analizadas como muestra de la naturalidad o espontaneidad dialógica, como la expresada por los enunciadores del ejemplo en la Tabla 9: 
Tabla 9. Ejemplo 7

== Si:: Exacto:: También 1 De manera que eso no:: (ac) no se aplica

FPP032014-06 de forma absoluta el 191 y el 149 que también:: también ale...alegaron 1 Es un artículo que está previsto dentro de la sección que ::regula:: a los funcionarios públicos y los diputados NO SON funcionarios públicos 1 Son diputados 1 EL ESTATUS de diputado es DISTINTO al de los funcionarios públicos y por tanto no se aplica a ese casol 1 Para destituir a un diputado solamente se puede destituir por sentencia firme del Tribunal Supremo de Justicia y ::por:: revocatorio del pueblo que lo eligió 1 (ac) y por supuesto por renuncia 1 que el diputado pueda renunciar ¿no? 1 Ninguno de esos supuestos está planteado 11 Pero es que María Corina Machado sigue teniendo investidura de diputado $1 \mathrm{El}$ señor Cabello ni la junta directiva tienen facultad para haberle quitado la investidura de diputada y esto ::puede:: crear un problema muy serio 11 En primer lugar un precedente muy grave [aspiración] Un problema serio y hasta de ::violencia:: porque María Corina Machado, que es una mujer muy valiente 1 ha dicho que va a acudir a la Asamblea Nacional a ocupar su cargo de diputada 1 que nadie se lo ha quitado 1 Nadie puede despojar 1 ninguno de los que lo despojó tiene facultad para despojar 11 ahí hay una violación 1 por supuesto también 1 de la Constitución Nacional 11 La han convertido 1 utilizando una expresión que ellos utilizan mucho 1 la han convertido en ::polvo cósmico:: ¿no? ll Esa constitución que tanto alabaron hoy (le) ya no existe 1 Aquí no existe sino una sola voluntad 1 que la voluntad de los que están gobernando 1 Eso es muy lamentable y estamos en presencia 1 Cuando eso es así 1 estamos en presencia de un gobierno DICTATORIAL 1 Un gobierno de hechos 1 que no tiene normas y no hay estado de derecho l es un gobierno de hechos dictatorial 1 muy peligroso para el venezolano 1 por eso yo:: yo creo que los venezolanos debemos seguir ::protestante:: frente a todo lo que está ocurriendo.

En su intervención, la fuente (un abogado) denuncia faltas graves a la ley, ocurridas durante la detención del líder de la oposición venezolana, Leopoldo López. Luego de largas explicaciones (dispositivo de conocimiento), el entrevistado llama "dictador" al Gobierno de dicho país, producto de la fluidez mostrada en sus contestaciones dado el estado de comodidad co-construido. Segundos después culmina la entrevista, descubriéndose la verdadera intención del periodista en la búsqueda de información. 
Con el propósito de lograr el contenido deseado, el entrevistador ejerce estrategias que garanticen un contexto de comodidad para la fuente de información, por lo que apela a valores y creencias como: ciudadanía activa, justicia, salud gratuita, trabajo decente y otros, que a su vez construyen el "yo" y el "nosotros", que, como establece (León, 2005), refuerzan ideologías y construyen la imagen propia y del otro, como se aprecia en la Tabla 10.

Tabla 10. Ejemplo 8

PCS052014- $==$ Exacto. ¿Y ustedes se ven afectados por este poco sueldo? En el 05 caso por ejemplo que muchas veces los intentan sobornar, mucho de los funcionarios matraquean a las personas ¿crees tú que puede ser por la falta de esto, la falta de sueldo?

FPS052014-05 == Exactamente, desde mi punto de vista que yo lo veo, es absurdo que que los comparo a nivel mundial, los países como Inglaterra, Holanda, e :: Suiza, Estados Unidos, el policía tiene los carros de los carros, II los policías tienen una casa en un sector acorde a su trabajo. Aquí no, aquí anda uno en buseta este :: , vive en los barrio, en los mismos barrios donde viven los ladrones que uno persigue 1 , este :: la los beneficios bueno los beneficios la le qué te puedo decir, osea por lo menos el seguro lamentablemente es es una basura, el seguro lo que cubre son 100 mil bolívares al AÑO que eso es nada (ac) , al AÑO, de hecho a da a Daniel cuando lo trasladaron desde el seguro hasta la clínica se consumió el seguro de él, se consumió el de la esposa y tuvimos que hacer una colecta para pagar ciento y pico mil de bolívares que dan el saldo cero por la clínica. I

PCS052014- $\quad:==$ Sí, es que eso es un coño cien mil bolívares al año. Y (inaudible) 06 y cuando alguno de ustedes, ni quiera Dios en tu caso (ac), lo los asesinan ¿Cómo hacen? ¿Les siguen pagando a sus familias? ¿Le siguen dando beneficios a la familia?

El entrevistador introduce una pregunta etéreamente (dispositivo rol interrogador ingenuo). El entrevistado compara su situación con la calidad de vida de policías en otros países (dispositivo de conocimiento) y refiere que no gozan de esta, con lo cual revela parte de su intimidad, sus carencias. Al describir su situación acelera el ritmo, como si esto le generase frustración. Para salir del momento de presión, se apoya en la historia de un colega. Acto seguido el periodista introduce la pregunta, con ideas que secundan lo expresado por el entrevistado (dispositivo de provocación), en señal de acuerdo. Para formular la pregunta incómoda por referirse a asesinatos, se apoya en una figura religiosa. 
Los hallazgos expuestos forman discursos completos o Movimientos que en su conjunto permiten comprender las intenciones de cada enunciador; dichas unidades de gran escala se adentran en un proceso interactivo para obtener o brindar información. Al analizar la conversación de lo particular a lo global, se comprende que en la interacción discursiva cada intervención o turno cumple una función. Sin embargo, no todos los turnos son evaluados a propósito de formar la tríada perfecta, sino que se convierten en grandes turnos seguidores en lo que más que un esquema u organización, persiguen el contenido.

Contrario a lo expuesto en las investigaciones consideradas como antecedentes y lo dicho en la literatura periodística, la espontaneidad (sin obviar que periodista y fuente pueden prediseñar su participación) resulta un elemento importante para el desarrollo de las entrevistas como método indagatorio de los medios impresos. Sin restricciones de tiempo y límites en el número de intervenciones, como sí ocurre en las entrevistas de radio y televisión analizadas por Gutiérrez (1997) y Marrufo (2005), los interlocutores logran expresarse de manera natural y plantear sus ideas, propósitos y estrategias a fin de llevar al otro hasta el punto discursivo de su conveniencia.

No son los esquemas rígidos maniobras propias de las entrevistas realizadas por periodistas de medios de comunicación impresos, sino que es la calidad de los contenidos la estrategia y el propósito a la vez, los cuales se expresan a través de turnos seguidores y el replanteamiento de las consultas a partir de múltiples habilidades de compenetración en el desarrollo de los temas y el replanteamiento de las ideas.

Como expone Charaudeau (2003), se trata de patrones de un tipo de interacción espontánea, periodista - fuente, que resulta cuando se produce una palabra de información fática inmediata o de contacto, próxima a la confesión, de análisis en caliente hecha de comparaciones y metáforas o relatos evocadores que, tanto en la radio como en la entrevista como método para medio impreso, resultan de la interacción verbal.

\section{CONCLUSIÓN}

Los enunciadores de la entrevista periodística como proceso dialogado inician la conversación con intenciones preestablecidas y adaptadas al contrato comunicativo que los convoca. Aunque se instituye socialmente quién pregunta y quién responde, las interacciones surgen a partir de la defensa de los intereses de los participantes. Por parte del periodista prima la búsqueda y obtención de información, y del entrevistado, brindar sólo el contenido que considera conveniente. En este sentido, se construyen estrategias de interacción que apelan a aspectos psicológicos y sociales (racionales y emocionales), a fin de mantener un encuentro dialogado cortés y colaborativo, que permita abordar aspectos de la intimidad del entrevistado y su grupo social.

En defensa de sus intereses, los interlocutores actúan con falsa inocencia, que permite al periodista, por ejemplo, consultar sobre temas importantes o susceptibles para 
la fuente, como la muerte. Para esto, emplean falsos comienzos como estrategia, a fin de plantear temas que luego trasladarán en el diálogo hacia aspectos que en primera instancia no habrían abordado de forma directa, ante posibles marcas de descortesía y pérdida de la confianza del otro. Los enunciadores emplean deícticos a modo de contextos sociales y espaciales que comparten como referencia para la construcción de sentido y coherencia de lo dicho.

El entrevistador puede incluso poner en riesgo su imagen como especialista en el área y mostrarse como desconocedor de ciertos aspectos para lograr que el entrevistado brinde mayor contenido.

La fuente, por su parte, también usa la falsa inocencia cuando desea evadir la pregunta incómoda o preparar su respuesta. Al referirse a terceros o temas delicados, los enunciadores emplean el uso de la polifonía, para así tomar distancia del mensaje.

A propósito de abordar temáticas de interés público y de características complejas, las conversaciones se apoyan en contextos sociales amplios que permiten al entrevistador trasladar al entrevistado a través de variados tópicos hasta mantenerlo en una zona de comodidad, en la cual el periodista se permite a sí mismo interrogarlo sobre temas de interés para su propio espacio público, construido bajo una visión que equivale a la realidad.

La entrevista puede desarrollarse en una compleja red de interacciones semánticas, formadas por unidades discursivas que constituyen el texto, por lo que se señala que son las Tríadas de Contenido, que relacionan el discurso con el mundo de los acontecimientos, las de mayor uso en la evidencia analizada. La importancia de evaluar estos esquemas, desde el Turno de Habla hasta el Texto Artefacto, radica en el hecho de que al enlazar los Movimientos, conformados por la Tríada, y observar la relación entre las partes, es posible valorar la intención del periodista y la fuente. Sin embargo, el valor de los contenidos no se aprecia en el cumplimiento de la estructura formal de Turno Iniciador - Turno Seguidor - Turno de Cierre, sino en el seguimiento, la evaluación y los cambios espontáneos de los temas, puesto que la conversación se construye con cada participación de los hablantes, ya que el discurso es un texto vivo, versátil y rico en significados. Más allá de la estructura, se impone el propósito de informar y representar a sus grupos como fuente de información.

Entre las estrategias también se reconoce el uso de fatemas con significado interactivo y como Turno Seguidor que organiza el discurso. Entrevistado y entrevistador, igualmente, recurren a hiperónimos, para realizar múltiples referencias a la realidad. Asimismo, predomina el uso de halagos al entrevistado, su labor o causa, con el objeto de que se sienta cómodo durante la conversación y no muestre limitaciones para compartir la información.

No prima el rol del periodista poderoso, ni se centra el encuentro dialogado en polémicas. El entrevistador se presenta como traductor de una realidad y en su papel de mediador da importancia a los sentimientos del otro, a fin de mostrar a su informante 
como miembro de una sociedad, en caso de que así lo amerite la instancia mediática, en función de cómo imaginen que lo interpretará la instancia receptora, su audiencia, como parte del proceso de transacción del contrato de comunicación.

A pesar de la estructura flexible de las entrevistas, es el entrevistador quien mantiene el control durante la mayor parte de la conversación, a través de la pregunta y sugerencia de temas a partir de los turnos iniciadores, secundados por el entrevistado con su respuesta. El mayor número de intervenciones es del periodista, quien evalúa y cierra la tríada; sin embargo, los turnos de mayor duración son del informante, ya que lo primordial en la conversación es la información que se obtiene a través de este como fuente viva, sin restricciones de tiempo, lo que propicia mayor grado de colaboración entre las partes y construcción conjunta de significados. A menor número de silencios prolongados, mayor es el sentido interactivo.

La presente investigación determina que en las entrevistas analizadas no imperan las estructuras rígidas de una conversación con la determinación de los roles: Interrogador-Interrogado; domina la expresión de contenidos de calidad informativa coconstruidos a partir de estrategias de compenetración en el desarrollo de los tópicos.

Vale destacar que las fuentes vivas de información, basadas en sus propósitos personales y grupales, muestran múltiples roles y no sólo el carácter profesional por el que son convocadas como informantes, como cuando el funcionario policial también se mostró como ciudadano, padre de familia y víctima del hampa o el abogado se expresó como venezolano. Tanto informantes como periodistas emplean la representación grupal para justificar sus actos y fines. Con esto también protegen sus intereses y recursos, aun cuando sean ilegales o injustos, como el soborno, acción de una carga semántica mitigada a partir de expresiones conjugadas en primera persona del plural, para representar "nuestras malas cosas" y las "malas cosas de ellos", lo que favorece la polarización extrema de los grupos sociales.

En escena se ponen en juego construcciones ideológicas y de imagen que a modo de sugerencia merecen ser analizadas, a propósito de comprender aún más la interacción periodista-fuente en la entrevista como método de indagación o recolección de información en medios impresos. Asimismo, se observa el uso estratégico de fatemas, hiperónimos, deícticos y polifonía con significado interactivo, que aportan a la construcción de sentido y coherencia del discurso, por lo que igualmente se sugieren como posibilidad de estudio.

\section{REFERENCIAS}

Bolívar, A. (2005). Discurso e interacción en el texto escrito (2 ${ }^{\underline{a}}$ ed.). Universidad Central de Venezuela.

Calsamiglia, H., y Tusón, A. (2012). Las cosas del decir: Manual de análisis del discurso (3ª ed.). Editorial Ariel. 
Charaudeau, P. (2003). El discurso de la información. La construcción del espejo social (Trad. M. Mizraji). Gedisa. (Obra original publicada en 1997, bajo el título de Le discours d'information médiátique. Éditions NATHAN/HER).

Dragnic, O. (2010). Diccionario de comunicación social. Panapo.

Escandell, M (1996). Introducción a la pragmática. Editorial Ariel.

Goffman, E. (1964). The Neglected Situation. The Ethnography of Communication. American Anthropologist, vol 66(6). http://www.jstor.org/stable/668167.

Goffman, E. (1967). Ritual de la interacción. Ensayos sobre el comportamiento cara a cara. Tiempo Contemporáneo.

Gumperz, J. (1982). Discourse Strategies. https://doi.org/10.1017/CBO9780511611834.

Gutiérrez, S. (1997). Temas, remas, focos, tópicos y comentarios. Arco Libros.

León, F. (2005). Análisis del discurso político populista latinoamericano. Un enfoque semánticopragmático (Tesis de Maestría). Universidad del Zulia, Zulia, Venezuela.

Lewandowski, T. (2000). Diccionario de lingüística (Trads. M.L. García, D. Navarro y E. Bernárdez). Cátedra.

Marrufo, K. (2005). Estrategias interaccionales empleadas por el entrevistador para provocar, orientar y condicionar el evento comunicacional en la entrevista televisiva venezolana (caso Televen) (Tesis de Maestría). Universidad Pedagógica Experimental Libertador Luis Beltrán Prieto Figueroa, Barquisimeto, Venezuela.

Méndez, D. (2011). Estrategias de Cortesía y elaboración de la imagen en el discurso periodístico de los moderadores del programa "Entre periodistas" (Tesis de Maestría). Universidad Pedagógica Experimental Libertador Luis Beltrán Prieto Figueroa, Barquisimeto, Venezuela.

Reguera, A. (2012). Metodología de la investigación lingüística. Prácticas de escritura (2ª ed.). Editorial Brujas.

Rojas, B. (2010). Investigación cualitativa. Fundamentos y praxis. (2ª ed.) FEDUPEL.

Rusque, A. (2003). De la diversidad a la unidad en la investigación cualitativa. Vadell Hermanos Editores.

Sal, J., y Maldonado, S. (2009). Estrategias discursivas: Un abordaje terminológico. Espéculo, (43). https://webs.ucm.es/info/especulo/numero43/abotermi.html.

Tusón, A. (1997). Análisis de la conversación. Editorial Ariel S.A.

Van Dijk, T. (1997). Racismo y análisis crítico de los medios (Trad. M. Baste). Editorial Paidós.

Van Dijk, T. (1999). Ideología. Una aproximación multidisciplinaria (Trad. L. Berrone). Gedisa. (Obra original publicada en 1998, bajo el título de Ideology:A Multidisciplinary Approch. Sage Publications). 